\title{
Herbage quality in Rhodes grass (Chloris gayana Kunth). 1. The effect of heading date on intra-variety variation in yield and digestibility in vitro
}

J. G. Boonman

National Agricultural Research Station, Kitale, Kenya

Accepted: 22 February 1978

Key words: Chloris gayana Kunth, Rhodes grass, intra-variety variation, heading date, seed yield, herbage yield, in vitro digestibility, leaf and stem fractions

\section{Summary}

350 selected plants of Mbarara (early-heading), Masaba (medium-heading) and Pokot (late-heading) Rhodes were examined for both seed and herbage yield characters, the latter at the stage of initial heading.

Within each of these varieties a large variation occurred between individual, spaced plants in seed and herbage yield, leaf/stem ratio and organic matter digestibility in vitro (D-vitro). However, this variation was secondary, as it was largely accounted for by a wide variation in heading date, ranging over 8 weeks or more within a variety. There was a progressive decline in yield characters with every week of delayed heading.

Early-heading plants produced yields of PGS (pure germinating seed) more than double those of late plants. At the initial-heading stage these plants also had a higher herbage yield, leaf/stem ratio and D-vitro, but a lower \% stem and dead leaf. D-vitro was on average 7.6 units higher in early plants than in plants heading 8 weeks later, but the extremes varied as much as 17 units between some early and late.

D-vitro of leaf, stem and whole-sward samples fell by $0.07,0.12$ and 0.14 units, respectively, with every day of delayed heading. Leaf digestibility and \% dry matter were higher than those of stems.

At the initial-heading stage whole-sward digestibility and leaf/stem ratio were higher in Mbarara than in Masaba and Pokot, because Mbarara plants were on the whole earlier in heading. Of those plants, however, which had a common heading date in each of the 3 varieties, i.e. which were sampled at the initialheading stage and on the same day, digestibility and leaf/stem ratios of Masaba plants were above those of Mbarara and, in particular, those of Pokot. 


\section{Introduction}

Cultivated varieties of cross-fertilizing tropical grasses in Kenya are characterized by a wide intra-variety range in heading date between individual plants, usually about 6 weeks between the first and the last $5 \%$ of the plants to come into head (Boonman, 1971; Boonman \& van Wijk, 1973). This variation is wider than the 4 weeks between varieties within a species (Boonman \& van Wijk, 1973; van Wijk, 1976).

The origin and development of this variation in Rhodes grass (Chloris gayana Kunth) was described by Boonman (1978) as an adaption to rainfall patterns in the habitat where the original ecotypes were collected in the 1950s and to the system of continuous seed multiplication imposed after introduction.

Evidently, such a variation in heading date was not compatible with varietal stability nor with maximum seed yield (Boonman, 1971). Of positive practical importance was that these varieties also contained a wide variability in herbage and seed yield, sward persistence and herbage quality, which could be largely accounted for in terms of the above variation in heading date. It was found that late-heading plants were progressively poorer in these characters (Boonman, 1978).

Thus, the observed intra-variety variation in yield characters is a secondary variation, as it depends on the primary variation in heading date. 'Primary' is here taken to denote 'first recognizable', rather than to indicate a causal relationship.

Traditionally late-heading species and varieties have been widely favoured in agriculture as they provide vegetative herbage over a longer period of growth. However, more recent studies on temperature grasses reviewed by Mowat (1968) show that 'with grasses cut at the same stage of maturity, the more digestible species are those harvested earliest; the picture is much similar within a species'. Raymond (1969) stated that within species and at a similar stage of development late varieties tend to be less digestible than early varieties because both stem and leaf fractions are somewhat less digestible and because they contain a higher proportion of senescent and dead material. Deinum \& Dirven (1971), on the other hand, have implicated climate and have emphasized that the effect of ageing on quality in spring in temperate climates is mainly due to rising temperatures. They suggested that in constant climates the effect of ageing on digestibility would be small.

At Kitale $\left(1^{\circ} 1^{\prime} N\right)$ not only daylength but also mean daily temperatures are virtually constant throughout the growing season (Boonman, 1973). Consequently, it was of interest to study the intra-variety variation, already noted, and the effect differences in heading date or age have on yield and digestibility of genotypes at the same stages of maturity. This was done for each of the three commercial Rhodes grass varieties, Mbarara (early-heading), Masaba (medium-heading) and Pokot (late-heading). Thus, ancillary to the information on the effects of difference in heading date between varieties the present study attempts to cast light on the effects of difference in heading date within these varieties. 
Herbage characteristics were measured at the initial-heading stage of each plant, so that comparisons could be drawn that do justice to the actual differences in development between varieties and between individual plants. Moreover, a comparison of plants with a common heading date across the 3 varieties made it possible to assess the true effects of varieties, without the confounding effects of age and stage of development.

\section{Materials and methods}

Of 100, 150 and 100 selected genotypes of Mbarara, Masaba and Pokot Rhodes, respectively, $2.5-\mathrm{m}^{2}$ swards were established vegetatively in November 1973 . The 3 varieties were in adjacent blocks. Individual swards were separated by $30-\mathrm{cm}$ paths sown to Brachiaria ruziziensis Germain et Everard.

Establishment was uneven and no recording was possible until 1975 when the swards were investigated for yield of PGS (pure germinating seed) after a cleaning cut and top-dressing with ammonium sulphate nitrate at $100 \mathrm{~kg} \mathrm{~N}$ per ha on 24 April. Mid April 1976 the plots were given the same treatment and were left to grow until 30-50 heads were counted as actually present per $\mathrm{m}^{2}$, in countings carried out weekly. At this stage, defined here as initial heading, the sward was cut, weighed and a sample was drawn for $\%$ dry matter and in vitro organic matter digestibility, D-vitro (Tilley \& Terry, 1963). Another sample of $250 \mathrm{~g}$ was drawn for separation into leaf lamina, stem including leaf sheath, dead Rhodes grass material and weeds, and for subsequent analysis of in vitro digestibility of the leaf and stem fractions. Leaf and stem separation was always completed within 3 hours after harvesting, yet water losses were apparent in that the $\%$ dry matter of the original unseparated sample was always 2 - 3 units lower. The samples were dried at $100{ }^{\circ} \mathrm{C}$ in a forced-draught oven and a grinder screen with $1-\mathrm{mm}$ apertures was used.

In this study \% dead leaf and \% stem, based on the original unseparated sample, are presented also as it difficult to account for dead plant material and weeds in the usual leaf/stem ratios.

Sampling began on 28 June and lasted until 20 September, involving 13 weekly samplings.

\section{Results and discussion}

Table 1 shows the data on variety averages which were weighted over the number of plants present at each sampling of 1976. The PGS yield data of 1975 are also included in this table. In Fig. 1 the straight means of each sampling date were used to compute linear or quadratic regressions. Individual varieties are presented in the graphs only when all three varieties produced significant effects of heading date, failing which data were pooled and presented for all three together, provided that the data showed a significant effect when combined.

Mbarara was the first to begin heading, followed by Masaba and finally Pokot 
Table 1. Main plant characters; weighted averages; 1976 data taken when $30-50$ heads had emerged per $\mathrm{m}^{2}$.

\begin{tabular}{|c|c|c|c|}
\hline Parameter & Mbarara & Masaba & Pokot \\
\hline Number of plants & 100 & 150 & 100 \\
\hline $\begin{array}{l}1975 \\
\text { yield of PGS }(\mathrm{kg} / \mathrm{ha}) \\
\text { number of heads per } \mathrm{m}^{2} \\
\text { PGS per head }(\mathrm{mg})\end{array}$ & $\begin{array}{l}35.0 \\
274 \\
12.7\end{array}$ & $\begin{array}{l}29.4 \\
313 \\
9.3\end{array}$ & $\begin{array}{l}11.5 \\
172 \\
6.6\end{array}$ \\
\hline $\begin{array}{l}1976 \\
\text { mean heading date } \\
\text { dry matter yield }\left(\mathrm{kg} \mathrm{ha}^{-1}\right) \\
\text { dry matter yield }\left(\mathrm{kg} \mathrm{ha}^{-1} \text { day }^{-1}\right) \\
\text { leaf/stem ratio } \\
\text { stem }(\%) \\
\text { digestibility in vitro (D-vitro) } \\
\text { leaf }\left(D_{1}\right) \\
\text { stem }\left(D_{s}\right) \\
\text { whole sward }\left(D_{w}\right)\end{array}$ & $\begin{array}{l}25 \text { July } \\
2700 \\
26.9 \\
0.68 \\
56.6\end{array}$ & $\begin{array}{l}8 \text { August } \\
2940 \\
25.4 \\
0.65 \\
55.7\end{array}$ & $\begin{array}{l}26 \text { August } \\
2600 \\
20.1 \\
0.47 \\
61.4\end{array}$ \\
\hline
\end{tabular}

(Table 1). The intervals in heading date were in agreement with Boonman \& van Wijk (1973).

PGS yield, head number and PGS weight per head dropped sharply as plants came into head later (Fig. 1). PGS yields were reduced to half within 2-3 weeks, which was due to either a parallel decline in head numbers (Mbarara and Masaba) or to a drop in PGS weight per head, namely in Pokot which had only a small, though significant, decrease in head numbers. The weighted mean PGS yields of Mbarara and Masaba did not differ much, but those of Pokot were about one third of the other two (Table 1). Generally, there was no correlation between the clean seed yield of a plant and its percentage germination $\left(r_{87}=0.09\right)$ so that each plant needed a separate germination test.

The yield of dry matter (DM) dropped, on the average, by over one third, even though the growth period doubled from 12 weeks for the plants heading in the first week $\left(W_{1}\right)$ to 24 weeks at $W_{13}$ (Fig. 1). Consequently, DM yield per day fell from 40 at $W_{1}$ to $10 \mathrm{~kg}$ at $W_{13}$. A recovery was evident from $W_{7}$ onwards in Mbarara, both in DM and PGS yield. Some evidence to this effect had been noticed before, which led to renewed though unsuccessful attempts of searching for more extremely-late heading Mbarara plants.

Leaves had a higher \% DM than stems, the differences becoming wider as plants came into head later (Fig. 1). Generally \% DM of leaf and stem increased with 1.0 and 0.8 unit, respectively, with each week of delayed heading. At any given sampling date Mbarara was higher in \% DM than either Masaba or Pokot (Fig. 1), but its weighted means were lower due to its earlier heading (data not presented).

As plants came into head later, leaf/stem ratios (LSR) dropped, \% stem and 
dead leaf increased and the digestibility of leaf $\left(D_{1}\right)$, stem $\left(D_{\mathrm{B}}\right)$ and the wholesward sample $\left(D_{w}\right)$ decreased (Fig. 1). In Pokot LSR dropped only slightly which agrees with the slight drop already noted in head number. Similarly, \% stem was hardly increased by heading date in Pokot unlike in Mbarara and Masaba (data
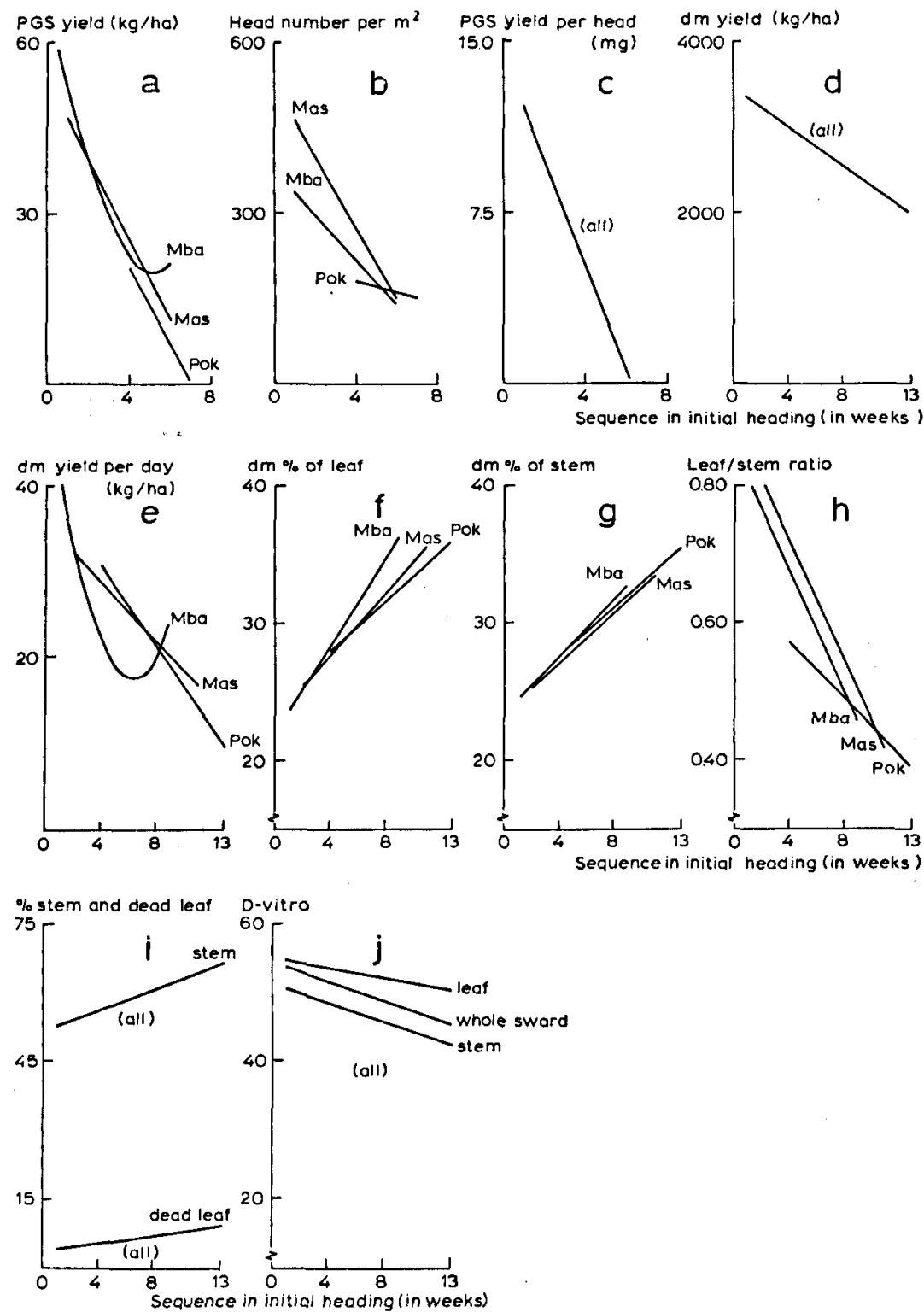

Fig. 1. Regression on intra-variety differences in date of initial heading (in weeks); $1, \ldots$, 13: plants commencing heading in the $1 \mathrm{st}, \ldots$, 13th week of heading; $a, b$, c: data taken at seed harvest, 1975; d, e, f, g, h, i, j: data taken at initial-head emergence stage of each plant, 1976; $\mathrm{Mba}=$ Mbarara; Mas $=$ Masaba; Pok $=$ Pokot; all: all varieties pooled. 
Table 2. A comparison of plants sampled at the same maturity stage (30-50 heads per $\left.\mathrm{m}^{2}\right)$ and at the same date (early August).

\begin{tabular}{llll}
\hline Parameter & Mbarara & Masaba & Pokot \\
Leaf/stem ratio & 0.54 & 0.63 & 0.48 \\
Digestibility in vitro (D-vitro) & & & 51.8 \\
leaf $\left(\mathrm{D}_{1}\right)$ & 50.9 & 50.2 & 45.2 \\
stem $\left(\mathrm{D}_{\mathrm{s}}\right)$ & 46.9 & 48.4 & 48.8 \\
whole sward $\left(\mathrm{D}_{\mathrm{w}}\right)$ & 49.7 & 50.5 & \\
\hline
\end{tabular}

not presented). However, the low LSR and the high \% stem of Pokot (Fig. 1 and Table 1) explain why $D_{w}$ was so much lower in Pokot than in the other varieties. Even though Pokot produces fewer flowering stems (Fig. 1 and Table 1) they are thicker than those of Masaba and, in particular, Mbarara (Bogdan, 1965).

At a given sampling date Masaba had a higher LSR than Mbarara (Fig. 1). However, late heading decreased LSR, so that the overall weighted LSR of the early-heading Mbarara was slightly above that of Masaba (Table 1). Late heading had a negative effect on digestibility too. Thus, $D_{w}$ was higher in Mbarara than in Masaba and Pokot because of its overall higher LSR, the higher digestibility of leaf than of stem, and the lower \% stem and dead leaf in early-heading plants.

In Table 1 varietal comparison is complicated by the fact that mean heading date, and, consequently, mean sampling date for herbage characters varied with the different varieties. Mbarara plants were on the whole superior, simply because they were younger at the initial-heading stage. To eliminate this confounding of age and heading date a comparison was made of those plants which had the same heading date and, therefore, the same sampling date in common in all 3 varieties. The samplings of 2 and 16 August $\left(\mathrm{W}_{6}\right.$ and $\left.\mathrm{W}_{8}\right)$ provided data of some $20-30$ plants of each variety with the same heading date (Table 2).

Masaba plants had a higher $D_{s}$ than either Mbarara or Pokot and, although $D_{1}$ was lower, Masaba's LSR was high enough to raise its $D_{w}$ above that of the other two. Pokot had the lowest LSR, $D_{s}$ and $D_{w}$. Therefore, Pokot digestibility is low not just because of its lateness in heading, but because of its poorer composition. In contrast, Masaba had a higher $L S R, D_{s}$ and $D_{w}$ than Mbarara (Fig. 1, Table 2).

Fig. 1 shows the decline in $D_{1}, D_{s}$ and $D_{w}$ with heading date of all varieties pooled per date of sampling. The effect of heading date was highly significant. $D_{1}, D_{8}$ and $D_{w}$ dropped with $0.07,0.12$ and 0.14 units, respectively, for every day of delayed heading. $D_{w}$ was almost equal to $D_{1}$ in the early-heading plants, but approached $D_{8}$ in late-heading plants, obviously due to the increase in $\%$ stem and dead leaf. As far as the individual varieties were concerned, heading date did not significantly decrease $D_{1}$ in any variety, decreased $D_{s}$ significantly in Masaba and Pokot only, but $D_{w}$ dropped significantly in all 3 varieties. $D_{w}$ of Masaba tended to be higher at most sampling dates but the differences were too small to come out clearly in graphs. 
The Masaba plants were screened individually for digestibility. The ranges were as follows:

leaf digestibility $\left(D_{1}\right) \quad 42-59$

stem digestibility $\left(D_{\mathrm{s}}\right) \quad 39-53$

whole-sward digestibility $\left(D_{w}\right) 39-56$

As noted above, these differences were largely due to differences in age. It was further found that the decline in digestibility with age did not depend on the herbage yield level. Masaba plants of different heading date but of similar yield levels gave the same decline in $D_{1}, D_{s}$ and $D_{w}$ with heading date as was reported above.

The data reported here for intra-variety variation in Rhodes grass are in agreement with the findings of van Wijk (1976) working with Setaria sphacelata, the second major sown grass in Kenya. Van Wijk observed that late-heading selections out of the Nandi variety were lower in digestibility than early-heading selections.

Also Clements (1973), studying variation in populations of Phalaris tuberosa in New Zealand, reported a negative correlation between digestibility and heading date.

The above differences between Pokot and the other varieties are important in that they refute earlier claims (Bogdan, 1965) that Pokot is leafy and of good herbage quality, whilst Mbarara is not. As a result, Pokot enjoyed great popularity in the 1960s and had the largest area under certified seed production of all Kenya commercial grasses (Boonman, 1971). In recent years, however, Pokot has fallen out of favour mainly because of its uneconomic levels of seed yield and because of low persistence. The data presented in this paper show that the late-heading Pokot is stemmy and of low digestibility, in contrast with Masaba which is also relatively late-heading. These differences in quality were independent of differences in heading date (Table 2).

It is concluded that within varieties of Rhodes grass a large variation occurs in PGS yield, herbage yield, leaf/stem ratio and digestibility, but this variation is secondary and can be largely explained on the basis of differences in heading date. Late heading results in low digestibility, which is accompanied by a progressive decline in leaf/stem ratios and a progressive increase in \% stem and dead leaf. Late heading had a more drastic effect on PGS yield than on herbage yield. Masaba was distinctly superior to Pokot in quality characteristics, irrespective of difference in mean heading date.

In a later article we will look at the variation between selected plants of similar heading date and sampled at fixed intervals.

\section{Acknowledgments}

I wish to thank Mr Z. Akwisiela and his staff for their assistance and Mr P. K. Njoroge for analysing the herbage samples. This paper is published with the permission of the Director of Research, Ministry of Agriculture, Nairobi. 


\section{HERBAGE QUALITY IN RHODES GRASS. 1}

\section{References}

Bogdan, A. V., 1965. Cultivated varieties of tropical and subtropical herbage plants in Kenya. E. Afr. agric. For. J. 30: 330-338.

Boonman, J. G., 1971. Experimental studies on seed production of tropical grasses in Kenya. 1. General introduction and analysis of problems. Neth. J. agric. Sci. 19: 23-36.

Boonman, J. G., 1973. On the seed production of tropical grasses in Kenya. Agric. Res. Rep. (Versl. landbouwk. Onderz.), 794. Pudoc, Wageningen.

Boonman, J. G., 1978. Rhodes grass breeding in Kenya. 1. Intra-variety variation and character relationships. Euphytica 27: 127-136.

Boonman, J. G. \& A. J. P. van Wijk, 1973. Experimental studies on the seed production of tropical grasses in Kenya. 7. The breeding for improved seed and herbage productivity. Neth. J. agric. Sci. 21: 12-23.

Olements, R. J., 1973. Breeding for improved nutritive value of Phalaris tuberosa herbage: an evaluation of alternative sources of genetic variation. Aust. J. agric. Res. 24: 21-34.

Deinum, B. \& J. G. P. Dirven, 1971. Climate, nitrogen and grass. 4. The influence of age on chemical composition and in vitro digestibility of maize (Zea mays L.) and tall fescue (Festuca arundinacea Schreb.) Neth. J. agric. Sci. 19: 264-272.

Mowat, D. N., 1968. Applications and implications of in vitro digestibility technique to plant breeding. IN: C. M. Harrison (Ed.), Forage Economics Quality Spec. Bull. Am. Soc. Agron. 13.

Raymond, W. F., 1969. The nutritive value of forage crops. Adv. Agron. 21: 1-108.

Tilley, J. M. A. \& R. A. Terry, 1963. A two-stage technique for the in vitro digestion of forage crops. J. Br. Grassld Soc. 18: 104-111.

Wijk, A. J. P. van, 1976. Herbage yield and quality relationships in 3 varieties of Setaria sphacelata (Schumach.) Stapf and Hubbard. Neth. J. agric. Sci. 24: 147-154. 